\title{
Muerte por proyectil de arma de fuego (PAF): procesamiento de la escena y hallazgos de necropsia. Morgue Central de Lima 2011
}

\author{
Denisse Astuhuamán, Shermany Aronés, Rosa Carrera, César Tejada, Róger Velásquez
}

Instituto de Medicina Legal, Ministerio Público, e Instituto de Patología, UNMSM

Introducción: La información del levantamiento de cadáver constituye la primera fase de la necropsia requerida para contrastarla con información obtenida, por lo que es primordial su estudio.

Objetivos: Revisión del procesamiento de escena y hallazgos de necropsia en casos de muerte por proyectil de arma de fuego (PAF).

Diseño: Descriptivo, retrospectivo, transversal.

Institución: Instituto de Medicina Legal, Ministerio Público, e Instituto de Patología, UNMSM.

Material de estudio: Informes de Levantamiento de Cadáver y Necropsia Medicolegal.

Intervenciones: Muestreo aleatorio por conglomerados, incluyendo informes de levantamiento de cadáver y necropsia de casos de muerte por PAF en el segundo semestre 2011.

Principales medidas de resultados: Medida de tendencia central, frecuencias y porcentaje.

Resultados: De 100 levantamientos de cadáver, hubo escena primaria (85\%), escena protegida (65\%), personal de criminalística PNP en escena $(85 \%)$, recojo arma de fuego $(20 \%)$, recuperación de proyectil $(45 \%)$, levantamiento de huellas dactilares $(35 \%)$, recolección de muestras de sangre $(90 \%)$, toma de muestras para absorción atómica $(87 \%)$, perennización de escena $(85 \%)$. La herida penetrante fue la más frecuente $(47 \%)$, con compromiso del segmento cabeza $(37 \%)$, disparo a larga distancia $(65 \%)$, etiología homicida $(90 \%)$.

Conclusiones: Los criterios utilizados para mejor evaluar la investigación pericial, antes no comprendidos, sirvieron para sistematizar la información requerida para mejorar la calidad pericial. La incidencia encontrada fue herida penetrante, cefálica, a larga distancia, escena primaria, perennizada, con recuperación de proyectiles en escena y necropsia.

Palabras clave: Escena crimen, proyectil de arma de fuego.

\section{Estudio epidemiológico de la enfermedad de Chagas en el Departamento de Amazonas, Perú: estudio del vector, reservorio humano}

Hilda Solís, Ana Huamán, Inés Garate, Alicia Diestro, Alejandro Ferrer, Graciela Ávila, Nelly Borja, Darío Esteban, Katy Tarqui, Sofía Espinoza, Nancy Carlos, Fanny Valverde

Instituto de Medicina Tropical Daniel A. Carrión, Facultad de Medicina, UNMSM

Objetivos: Determinar la presencia de enfermedad de Chagas y Trypanosoma cruzi, en reservorios humanos y animales, en localidades del departamento de Amazonas, Perú.

Diseño: Descriptivo, transversal.

Institución: Instituto de Medicina Tropical Daniel A. Carrión, Facultad de Medicina, UNMSM

Participantes: Pobladores de Quintaleros, el Ron, las 3 Marias, San Antonio, del distrito de Cajaruro, provincia de Utcubamba, departamento de Amazonas, Perú.

Intervenciones: Se viajó al Departamento de Amazonas, en mayo de 2011, para colectar los vectores.

Principales medidas de resultados: Presencia de enfermedad de Chagas y Trypanosoma cruzi.

Resultados: Se colectó los vectores de enfermedad de Chagas Panstrongylus herreri (Wygodzinsky, 1948), 131 especímenes (19 machos, 33 hembras, 79 ninfas y 92 huevos) y se encontró (15) triatominos infectados por T. cruzi; se les aisló en ratones Balb/C; se estudió la curva de parasitemia, encontrándose el pico a los 20 días. Al estudio morfométrico, se confirmó que correspondía a T. cruzi. Al estudio histopatológico, el tropismo se encontró en corazón y musculo esquelético. En los xenodiagnósticos de animales reservorios silvestres, 3 fueron positivos a T. cruzi. En 62 muestras de sangre de humanos, 4 fueron reactivos por serología.

Conclusiones: Existió la enfermedad de Chagas en las poblaciones estudiadas; se encontró el vector Panstrongylus herreri infectado por T. cruzi, domiciliado en la vivienda humana. Hubo humanos con serologia reactiva, así como reservorios animales infectados.

Palabras clave: Enfermedad de Chagas, Panstrongylus herreri, reservorios, Trypanosoma cruzi. 